\title{
EXPERIMENTAL PERFORMANCE EVALUATION OF PV/T PANELS AT NEGATIVE REDUCED TEMPERATURES
}

\author{
Riccardo Simonetti, Luca Molinaroli and Giampaolo Manzolini \\ Department of Energy, Politecnico di Milano, Via Lambruschini 4, 20156 Milano, (Italy)
}

\begin{abstract}
This work summarizes the performance of photovoltaic thermal panels integrated with a heat pump in a Solar Assisted Heat Pump (SAHP) system working with a negative reduced temperature. This concept brings about a higher electric production, due to the lower temperature of the panels, and that the heat produced by PV/T panels can be used also during winter period. A detailed experimental campaign was conducted in an outdoor laboratory in real ambient conditions to evaluate the performance of PV/T panels in this configuration. The results show a very high thermal efficiency, which go beyond the value of $200 \%$ due to the contribution of the convective heat transfer with the ambient, which has a higher temperature than the working fluid flowing inside the PV/T panels.
\end{abstract}

Keywords: Photovoltaic Thermal modules, Solar Assisted Heat Pumps.

\section{Introduction}

Photovoltaic thermal (PV/T) modules combine thermal and electricity production. (Chow, 2010) and (Kim \& Kim, 2012) have analyzed and demonstrated the potentiality of this technology, but the main drawback is the low thermal efficiency and stagnation temperature because of the high thermal losses (Zondag, et al., 2003) (Aste, et al., 2014). Insulation systems like vacuum chamber or the adoption of concentrators can be considered but require the installation of auxiliary rejection systems to control the PV cell temperature when the heat demand is absent (Kumar, et al., 2015). An option to exploit their potentiality keeping a simple module structure is the PV/T integration with a heat pump, leading to the so-called Solar-Assisted Heat Pump (SAHP) concept, where the heat recovered by the PV/T modules supplies the low temperature energy to the evaporator of the heat pump (Ji, et al., 2008). Different works described the advantages of this system with models and experimentation (Li, et al., 2014) (Calise, et al., 2016). In this configuration, the low stagnation temperature of the PV/T modules is not an issue due to the low operating temperatures of the working fluid and, moreover, the PV power output is higher than corresponding conventional PV module thanks to low cell temperature (Migliorini, et al., 2017). (Simonetti, et al., 2017) analyzed with a numerical model the behavior of a SAHP with roll-bond PV/T typology, confirming the energetic feasibility of the system and pointing out the working conditions of the panels, which could have a mean temperature of the cooling fluid under the ambient one. Experimental campaigns with temperatures below the ambient are not available in literature as the analysis is usually focus on the entire system (heat produced, energy consumption) and not on the PV/T subsection.

In this work, an experimental campaign was conducted at the laboratory SolarTech ${ }^{\mathrm{LAB}}$, Politecnico di Milano, to evaluate the behavior and the performance of PV/T panels coupled with a heat pump in different real ambient conditions, with particular focus on working conditions in which the mean temperature of the working fluid was below the ambient one.

The paper is structured as follow. Section 2 describes the experimental set-up, the PV/T modules, the measurement apparatus and the experimental conditions. Section 3 discusses the methodology adopted to collect and filter the data acquired. Section 4 presents the uncertainty analysis. In Section 5 results are presented and discussed. Finally, in Section 6 conclusions are drawn. 


\section{Experimental Facility}

The experimental set-up used in the present work is an outdoor laboratory whose layout is shown in Fig. 1. The experimental facility consists of: (i) a cold water loop (blue line), (ii) a water-to-water heat pump and (iii) a hot water loop (red line).

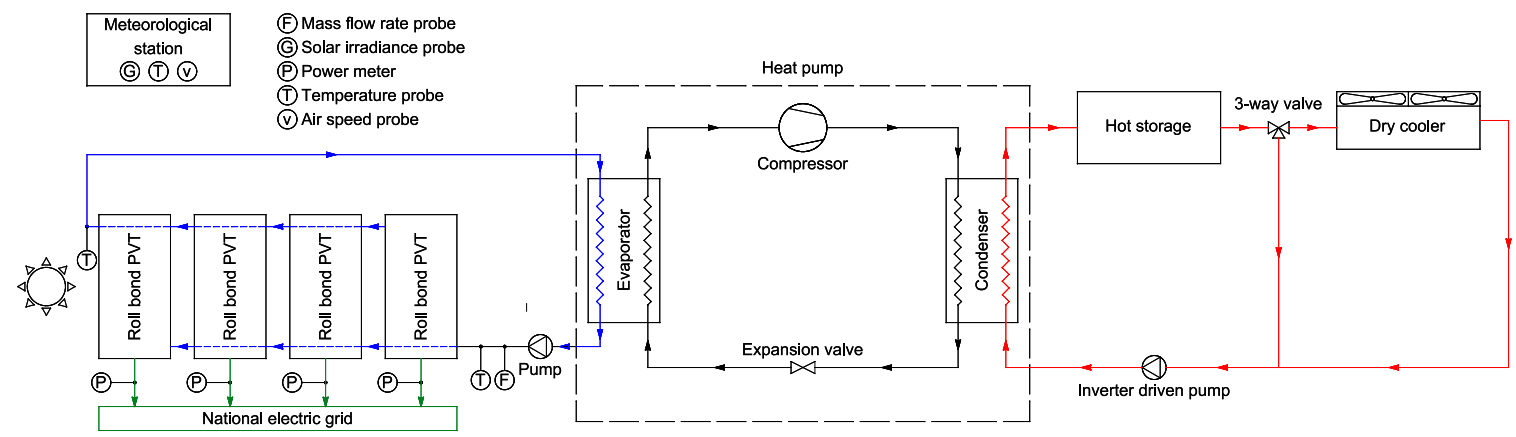

Fig. 1 - Schematic of the SAHP concept

In the cold water loop, the water at the outlet of four roll-bond PV/T collectors (SoLink, 2017) is used to feed the evaporator of the heat pump where it is cooled and sent back to the PV/T modules; the heat provided by the PV/T field acts as the low temperature heat source of the heat pump and the temperature achieved in the cold water loop may be lower than the ambient one which, in turn, increases both the electric and the thermal efficiency of the PV/T system.

In the hot water loop, the water is heated inside the condenser of the heat pump and sent to a hot storage tank. After that, thanks to a 3-ways valve, the fluid could directly return to the inlet of the condenser or pass through an air dry cooler. The fans of this component are automatically regulated to maintain the inlet temperature of the condenser of the HP stable and equal to a fixed value during experimentation.

\subsection{PV/T Modules}

As stated before, the PV/T modules adopts a roll-bond heat exchanger attached to the back of the module which recovers the excess heat, heating up a stream of water-glycol mixture. The roll-bond configuration allows an easy manufacturing as it is independent from the PV module which is a standard one. The solar cell is a polysilicon technology and the four panels have a heat exchanger circulation that allows to have a parallel configuration with simple tubes connection, as shown by the scheme in Fig. 2.
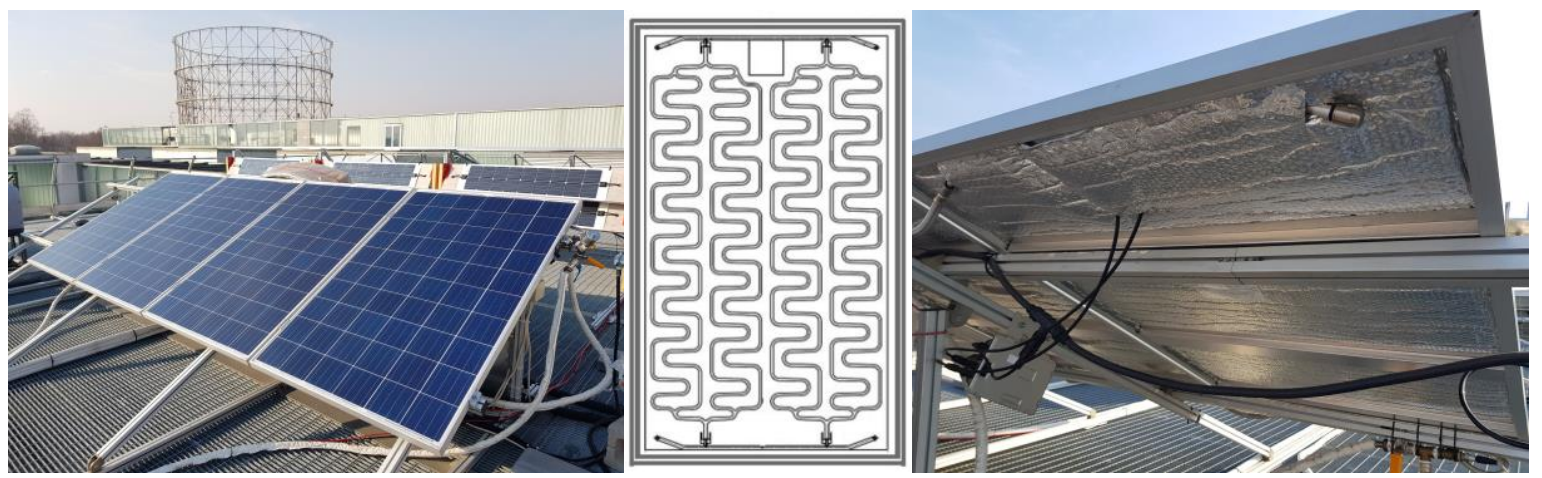

Fig. 2 - Front, circuitation and back of PV/T modules

The back of the modules is covered with an insulating layer (see Fig. 2), and each module is connected with its own inverter, in order to separately measure the electric performance of each.

Table 1 shows technical characteristics of the PV/T modules reported in the module datasheet. 
Table 1 - Technical characteristic of PV/T modules

\begin{tabular}{lr}
\hline Electrical Power Output & $250 \mathrm{~W}$ \\
Electrical Efficiency & $15.3 \%$ \\
Thermal Power Output & $850 \mathrm{~W}$ \\
Optical Efficiency & $52.3 \%$ \\
Thermal Losses Coefficient & $-13.8 \mathrm{~W} /\left(\mathrm{m}^{2} \mathrm{~K}\right)$ \\
Absorber Area & $1.63 \mathrm{~m}^{2}$
\end{tabular}

The PV/T modules are connected to a commercially available heat pump with a thermal power equal to $3.40 \mathrm{~kW}$ (a) $45^{\circ} \mathrm{C}$ and a COP equal to 4.09 .

\subsection{Measurement Apparatus}

The objective of the experimentation is to evaluate the thermal efficiency of the PV/T modules at different ambient conditions. The thermal efficiency is calculated as reported in the following equation:

$\eta_{\text {th }}=\frac{\dot{Q}_{\text {th }}}{\dot{Q}_{\text {in }}}=\frac{\dot{\boldsymbol{V}} \cdot \rho \cdot c \cdot\left(\boldsymbol{T}_{\text {out }}-\boldsymbol{T}_{\text {in }}\right)}{\boldsymbol{G}_{\boldsymbol{T}} \cdot A_{\text {panel }} N_{\text {panels }}}$

in bold, the measured variables, which are the inlet and outlet temperatures of the PV/T panels, the water flow rate and the solar irradiance, are reported. $\mathrm{G}_{\mathrm{T}}$ is the solar irradiance on the panels aperture area. Also the ambient temperature measurement is required to evaluate the reduced temperature, according to eq. 2 :

$T_{R}=\frac{\left(\boldsymbol{T}_{\text {out }}+\boldsymbol{T}_{\text {in }}\right) / 2-\boldsymbol{T}_{\boldsymbol{a m b}}}{\boldsymbol{G}_{\boldsymbol{T}}}$

Temperature measurements are performed with thermoresistances Pt100 inserted in the hydraulic circuit. Volumetric flow rate measurements are performed with a flow meter whose operating principle is based on Von Karman's vortices: the flow rate is related to the frequency of this phenomenon. Furthermore, each PV/T module is connected with a micro-inverter that communicates with a computer to measure and maximize the power produced by each module. Finally, the laboratory is equipped with a weather station to monitor and collect experimental ambient data. Fig. 3 shows the configuration and the different weather measurement devices.

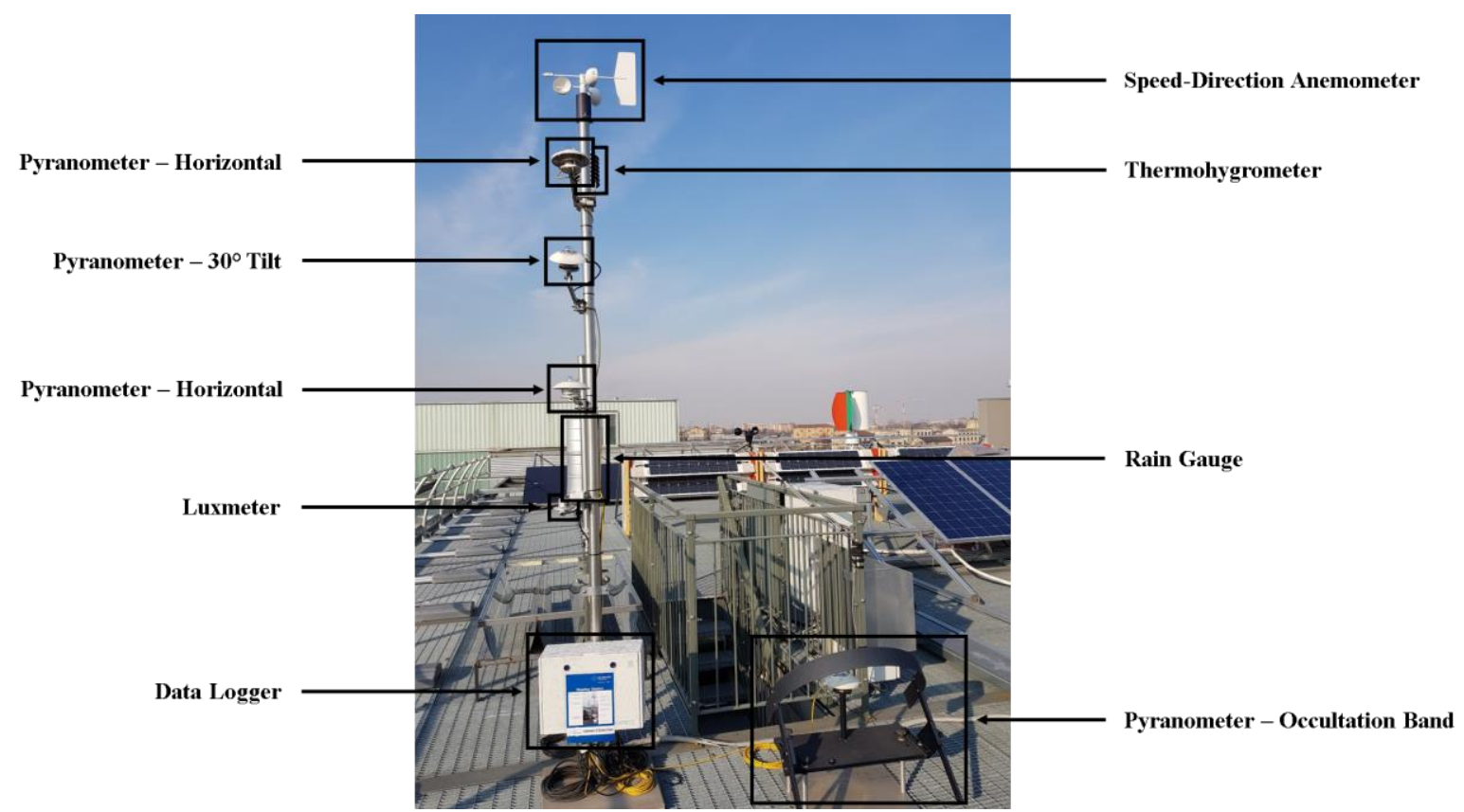

Fig. 3 - Weather station 
The station is equipped with the following measurement instruments:

- a thermohygrometer, measuring the air temperature and the atmospheric humidity

- two pyranometers, which determine the global solar irradiance on the horizontal plane (one first standard and one secondary standard)

- a secondary standard pyranometer that measures the global solar irradiance on a surface inclined at $30^{\circ}$

- a pyranometer with an occultation band, which detects the diffusive radiation

- a wind gauge to detect wind speed and direction

- a pluviometer to measure the amount of rain

$\mathrm{G}_{\mathrm{T}}$ can be calculated from the measurements of the global solar irradiance on the horizontal plane $\mathrm{G}_{\mathrm{G}, \mathrm{H}}$, the diffuse solar irradiance $G_{D, H}$, the position of the sun in the sky $\left(\theta_{z}\right.$ and $\left.\gamma_{s}\right)$, the orientation of the panels respect to the South $\gamma$ and the inclination respect to the Zenith $\beta$ according to the following equations:

$\cos \vartheta=\cos \vartheta_{z} \cdot \cos \beta+\sin \theta_{z} \cdot \sin \beta \cdot \cos \left(\gamma-\gamma_{s}\right)$

$G_{T}=\left(G_{G, H}-G_{D, H}\right) \cdot \frac{\cos \theta}{\cos \theta_{z}}+G_{D, H} \cdot \frac{1+\cos \beta}{2}$

Detailed data of the instruments are reported in Table 2.

Table 2 - Technical information of the measurement instruments

\begin{tabular}{lccc}
\hline \multicolumn{1}{c}{ Instrument } & Model & Range & Uncertainty \\
\hline RTD & Pt 100 & $-50^{\circ} \mathrm{C}-250^{\circ} \mathrm{C}$ & $1 / 10 \mathrm{~B}$ (DIN EN 60751) \\
Flowmeter & Huba-Control -210 & $0.91 / \mathrm{min}-151 / \mathrm{min}$ & $\pm 1 \% \mathrm{FS}$ \\
Power meter (Inverter) & Power One - Aurora Micro & $<250 \mathrm{~W}$ & $\pm 1 \% \mathrm{RV}$ \\
Pyranometer & LSI - DPA 252 & $<2000 \mathrm{~W} / \mathrm{m}^{2}$ & $<2 \% \mathrm{RV}$ \\
Thermohygrometer & LSI - DMA 875 & $-30^{\circ} \mathrm{C}-70^{\circ} \mathrm{C}$ & $1 / 3 \mathrm{~B}$ (DIN EN 60751) \\
\hline
\end{tabular}

A National Instrument ${ }^{\mathrm{TM}}$ cRIO rack is used for data acquisition; data are sent via LAN to a host PC where a $\mathrm{LabVIEW}^{\mathrm{TM}}$ program is used to read, visualize, analyze and store the measurements. Data are read every second and saved in a file for further analysis and elaboration. Fig. 4 shows a screenshot of the developed program.

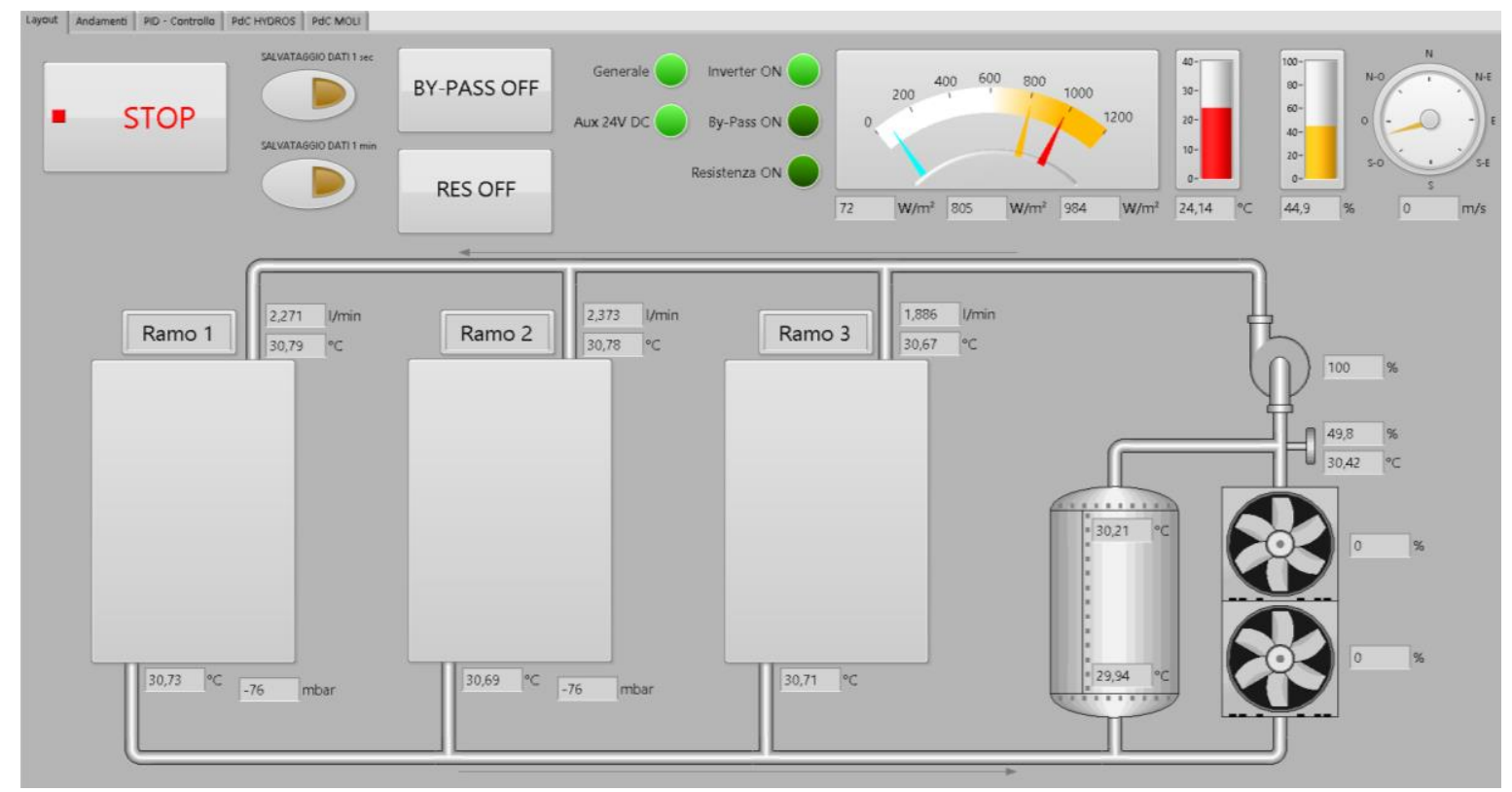

Fig. 4 - Screeshot of the control program 


\subsection{Experimental Conditions}

The experimental setup is located in the North of Italy, at SolarTech laboratory on the roof of the Department of Energy of Politecnico di Milano; whose geographical coordinates are latitude 45 $30^{\prime} 10.588^{\prime \prime} \mathrm{N}$ and longitude $9^{\circ} 9^{\prime} 23.677^{\prime \prime} \mathrm{E}$. PV/T panels are tilted of an angle of $27^{\circ}$ and oriented respect of the South of an angle of $-3^{\circ}$ (positive clockwise). A pump, controlled by the HP, completes the PV/T loop and a mixture of water and glycol is used to avoid freezing problems. Tests were carried out in the period from 13th of March to 26th of April 2018, 20 days of experimentation, with ambient temperature between $6.2^{\circ} \mathrm{C}$ and $29.0^{\circ} \mathrm{C}$ and solar irradiance of horizontal plane between $141.9 \mathrm{~W} / \mathrm{m}^{2}$ and $886.1 \mathrm{~W} / \mathrm{m}^{2}$. Fig. 5 shows example of temperatures trend during a day.

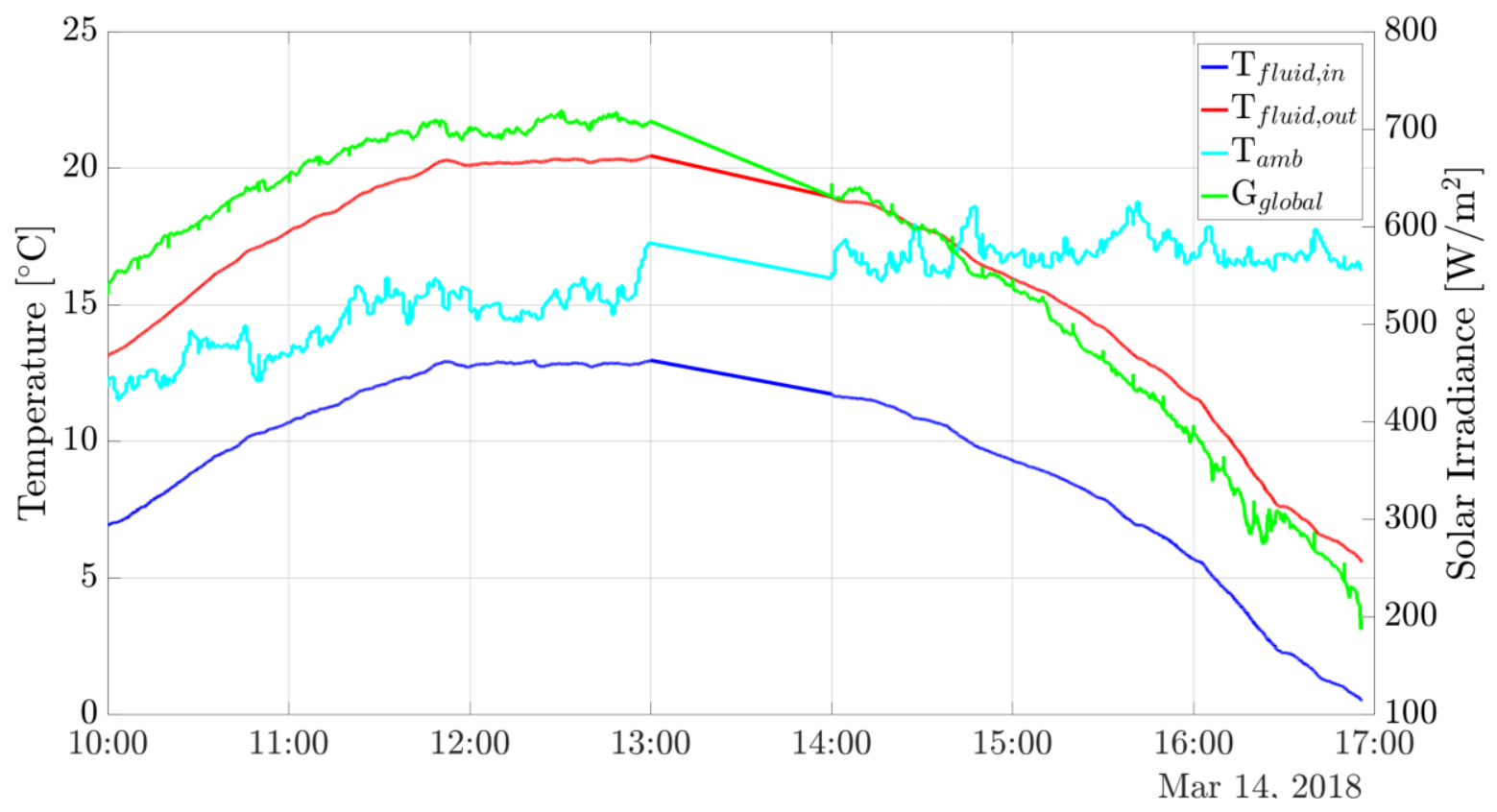

Fig. 5 - Temperatures at the inlet and outlet of the PV/T modules during a sunny day

\section{Methodology}

To improve the feasibility of the methodology to estimate the characteristic curve of PV/T modules, data filtering is required in order to avoid the inclusion of outliers and transient phenomena.

First step consists of selecting days with suitable weather conditions, meaning high and constant solar radiation and negligible wind. All the measured data are imported every second in MATLAB ${ }^{\circledR}$ where one-minute average value is calculated to smooth the variability. Then, steady state conditions of the system are ensured by applying some filtering criterions which all must be verified simultaneously; if only one of the filter fails for a certain minute, the whole data for that minute are neglected.

The set of variables and filters adopted in the process is summarized in Table 3.

Table 3 - Variable used for filtering and thresholds

\begin{tabular}{|c|c|}
\hline Control Bounds & $\dot{V}>0 l / m i n \& \dot{Q}_{t h}>0 \mathrm{~W}$ \\
\hline Flow Rate - Standard Deviation & $\sigma(\dot{V})<0.035 \mathrm{l} / \mathrm{min}$ \\
\hline $\mathrm{T}_{\text {in }} / \mathrm{T}_{\text {out }}-$ Variation between two minutes & $\Delta T<0.2^{\circ} \mathrm{C}$ \\
\hline $\mathrm{T}_{\text {in }} / \mathrm{T}_{\text {out }}-$ Standard Deviation & $\sigma(T)<0.05^{\circ} \mathrm{C}$ \\
\hline Solar Irradiance - Mean Value & $G>100 \mathrm{~W} / \mathrm{m}^{2}$ \\
\hline Solar Irradiance - Standard Deviation & $\sigma(G)_{\%}<1 \%$ \\
\hline
\end{tabular}


In Fig. 6 shows the application of the filter to the solar irradiance.

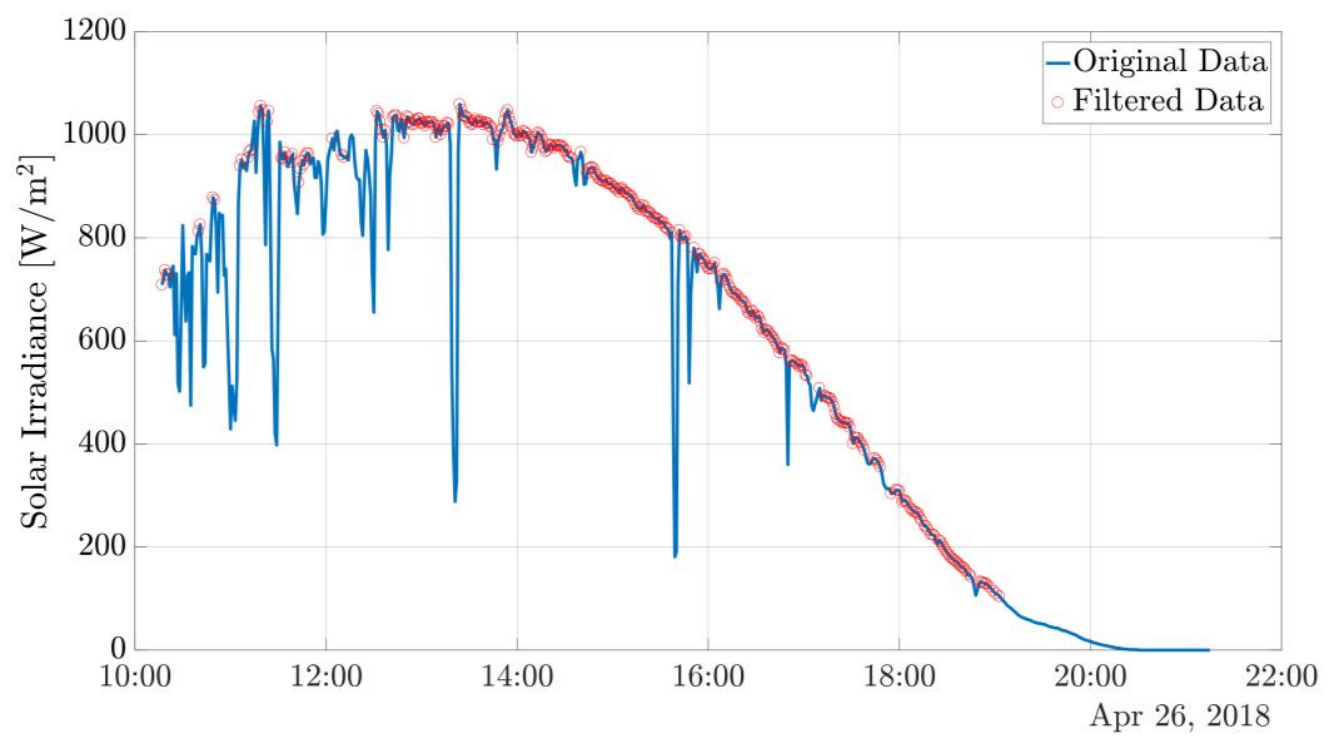

Fig. 6 - Example of data filtering

\section{Uncertainty Analysis}

Any experimental measurements have an error component, which could be small, but it always must be considered. In this way, the measured value is affected by uncertainty, so it is necessary to estimate quantitatively the quality of each single measurement. The evaluation of the uncertainty is related to the following equation:

$U\left(x_{i}\right)=\sqrt{U_{A}^{2}\left(x_{i}\right)+U_{B}^{2}\left(x_{i}\right)}$

The values measured every second are averaged in a window of one minute, hence an uncertainty of type $A$ is present. The sample is not large enough $(\mathrm{N}=60)$, thus it is necessary to adopt the $\mathrm{t}$-student distribution to predict the confidence interval of the measured data.

To evaluate the t-value, the degree of freedom (number of sample - 1) and the confidence level are required. For 59 degree of freedom and a $97.5 \%$ of confidence level, the t-value corresponds to 2.00 and uncertainty of type A can be calculated as follow:

$U_{A}\left(x_{i}\right)=t_{0.025} \cdot \frac{\sigma\left(x_{i}\right)}{\sqrt{N}}$

The uncertainties of quantities measured (uncertainty of type B) directly are evaluated referring to technical datasheets, whose main features are summarized in Table 2.

In order to estimate the uncertainty of indirect quantities, the propagation theory is applied: considering $\mathrm{y}$ as a generic quantity depending on the $\mathrm{M}$ samples of the direct quantities, calculated as $\mathrm{y}=\mathrm{y}\left(\mathrm{x}_{1}, \mathrm{x}_{2}, \ldots, \mathrm{x}_{\mathrm{j}}, \mathrm{x}_{\mathrm{M}}\right)$, its absolute uncertainty is computed with the equation:

$U(y)=\sqrt{\sum_{j=1}^{M}\left(\frac{\partial f}{\partial x}\right)^{2} \cdot U\left(x_{j}\right)^{2}}$

With this equation it is possible to calculate $U\left(\dot{Q}_{t h, i}\right)$ and $U\left(\eta_{t h, i}\right)$ by using the following expressions:

$$
\begin{aligned}
& U_{\%}\left(\dot{Q}_{t h, i}\right)=\sqrt{U_{\%}\left(\dot{V}_{i}\right)^{2}+\frac{1}{\left(T_{\text {out }, i}-T_{\text {in }, i}\right)^{2}} \cdot\left(U\left(T_{\text {out }, i}\right)^{2}+U\left(T_{\text {in }, i}\right)^{2}\right)} \\
& U_{\%}\left(\eta_{t h, i}\right)=\sqrt{U_{\%}\left(\dot{V}_{i}\right)^{2}+\frac{1}{\left(T_{\text {out }, i}-T_{\text {in }, i}\right)^{2}} \cdot\left(U\left(T_{\text {out }, i}\right)^{2}+U\left(T_{\text {in }, i}\right)^{2}\right)+U_{\%}\left(G_{T, i}\right)^{2}}
\end{aligned}
$$




\section{Results}

The aim of the experimental campaign is to determine the thermal efficiency curve for the PV/T modules as a function of the reduced temperature, according to eq. 10.

$\eta_{t h}=\eta_{o p t}+a_{1} \cdot \frac{\left(T_{o u t}+T_{\text {in }}\right) / 2-T_{a m b}}{G_{T}}$

In Fig. 7 it is reported the thermal efficiency vs. reduced temperature plot after the data filtering process explained in section 3, to remove all the measurements not in steady state condition. The regression line calculated according to eq. 10 is reported too.

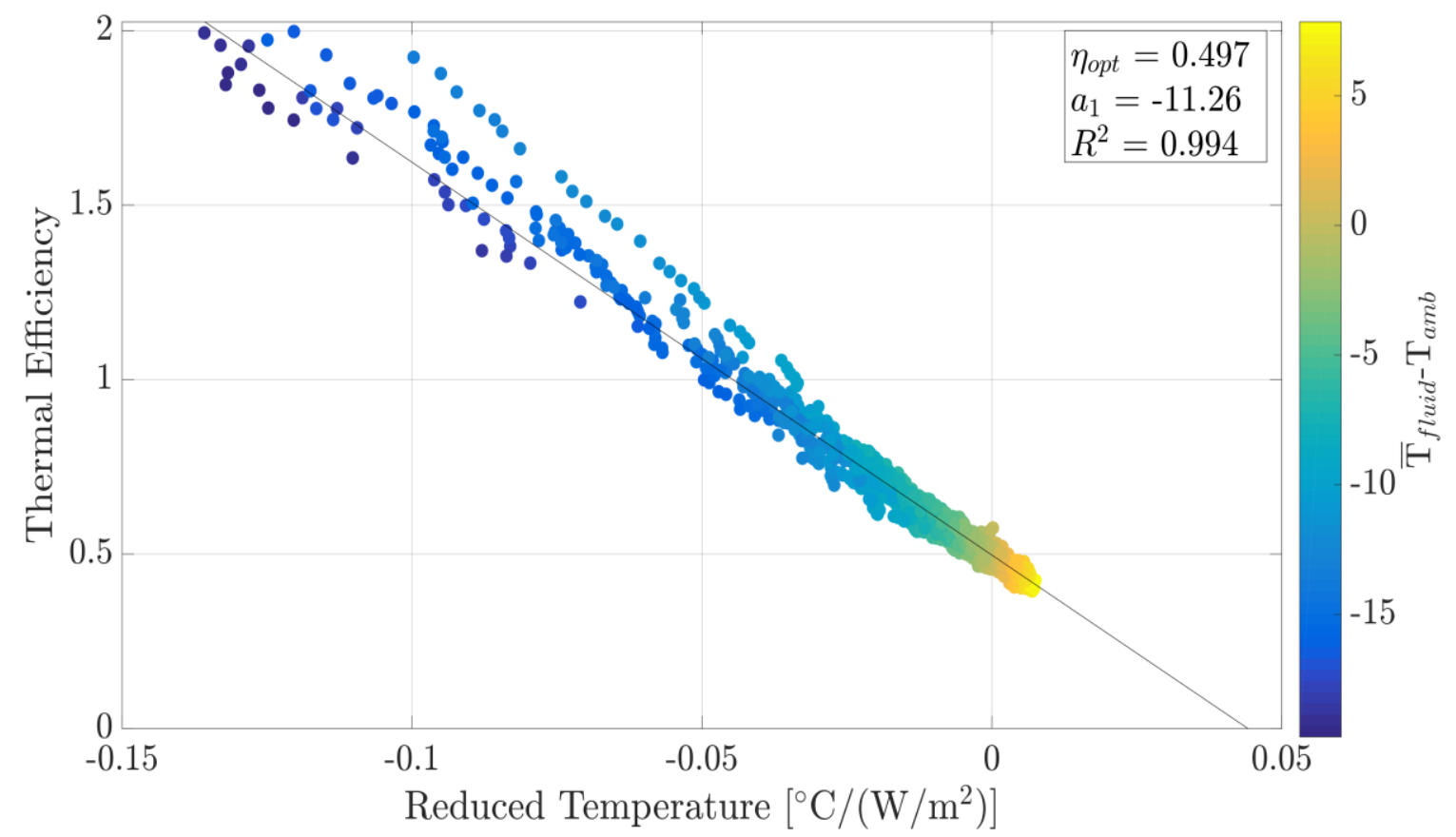

Fig. 7 - Thermal efficiency vs reduced temperature plot for all the PV/T measurements

Firstly, it is possible to see that all the measurements follow a linear trend, as expected by the theory. This is also confirmed by the parameter $\mathrm{R}^{2}$, which is higher than 0.99 , pointing out the goodness of the filtering process of the data and the possibility to evaluate the performance of PV/T panels also in real environmental conditions. The fluid mean temperature can reach values lower than $15 \mathrm{~K}$ with respect to the ambient temperature. Analyzing the results of the linear regression, we notice that both the optical efficiency $\eta_{\text {opt }}$ and the loss coefficient $\mathrm{a}_{1}$, equal to $49.7 \%$ and $-11.26 \mathrm{~W} /\left(\mathrm{m}^{2} \mathrm{~K}\right)$ respectively, are lower respect of the values present in the datasheet. This depends by the different laboratory typology (outdoor laboratory in this work and indoor one for datasheet) where the two characterization took place.

Therefore, thermal efficiency overcomes the optical efficiency in several cases, reaching also values near 2 for reduced temperatures around $-0.13^{\circ} \mathrm{C} /\left(\mathrm{W} / \mathrm{m}^{2}\right)$. Obviously, a condition with a very negative reduced temperature has not a real application: the aim of the experimentation is to confirm the linear trend of thermal efficiency also with the mean temperature of $\mathrm{PV} / \mathrm{T}$ panels significantly lower than the ambient one, removing the limit of some certificated PV/T curve characterization that need a high solar irradiance (higher than $\left.600 \mathrm{~W} / \mathrm{m}^{2}\right)$.

Results also confirm the advantages of the SAHP concept respect of a standard PV/T system: instead of producing directly the heat required by the house with a low thermal efficiency (especially during early spring and the last part of autumn), the heat is used to feed the HP, with a considerable higher thermal efficiency. A fraction of or all the electrical production of PV/T modules can also be used to supply the electrical consumption of the HP, reducing the exchanges with the national grid. 


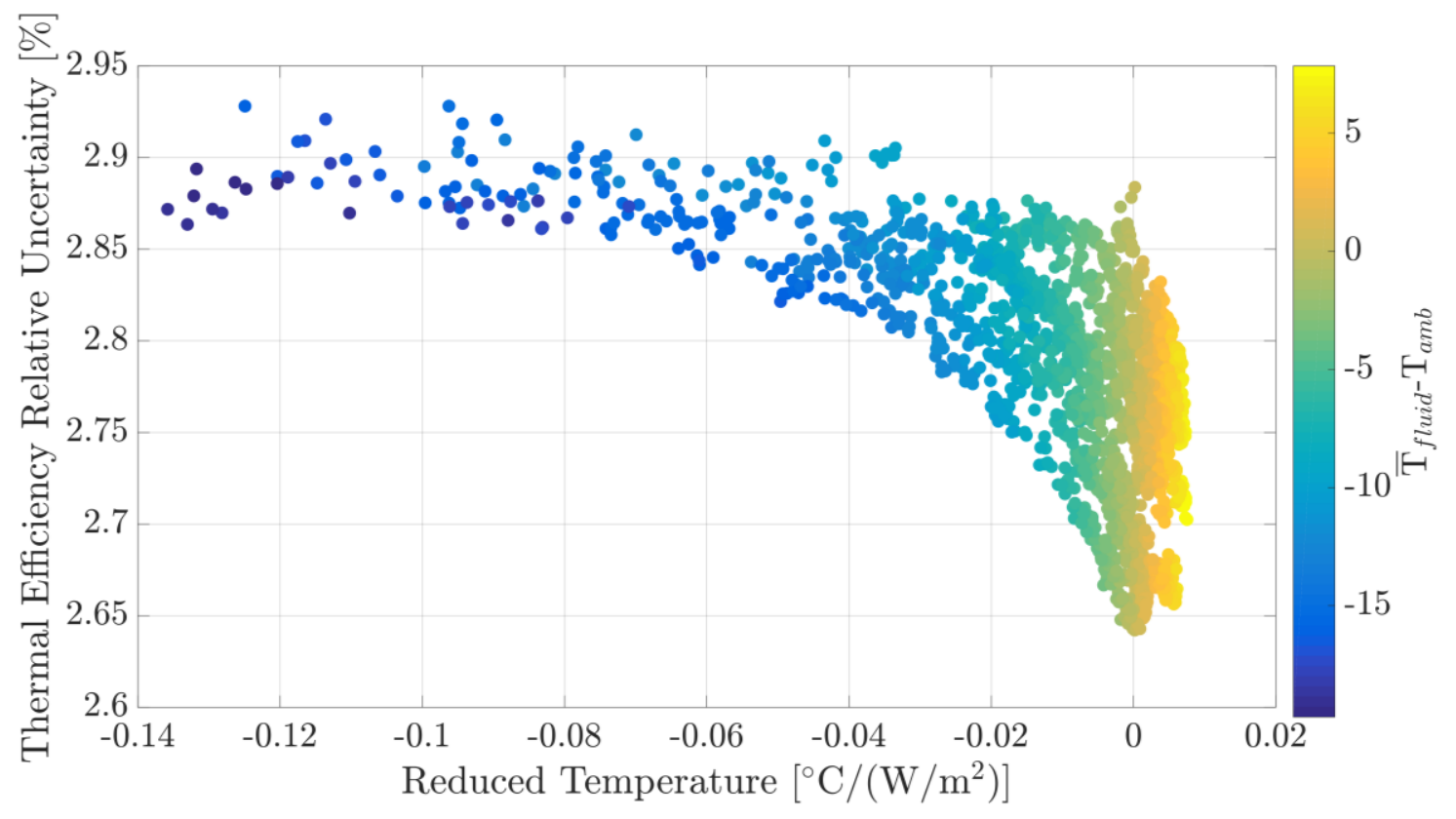

Fig. 8 - Thermal efficiency relative uncertainty vs. reduced temperature plot for all the PV/T measurements

Fig. 8 shows the relative uncertainty of thermal efficiency; it is possible to see that the fluctuation is inside a narrow band, varying between $2.65 \%$ and $2.95 \%$. This value is small and acceptable to consider reliable the data collected during the experimental campaign. Uncertainty increases with the decreasing of the reduced temperature, related to the reduction of the solar irradiance and the temperature difference between inlet and outlet of the panels. As can be deduced from Table 2, the highest contribute to the uncertainty value of thermal efficiency is given by the flowmeter instrument; to improve the quality of the measurement process, a substitution of this instrument can be done with another with lower uncertainty or lower full-scale (near the range of the flow rate user for testing).

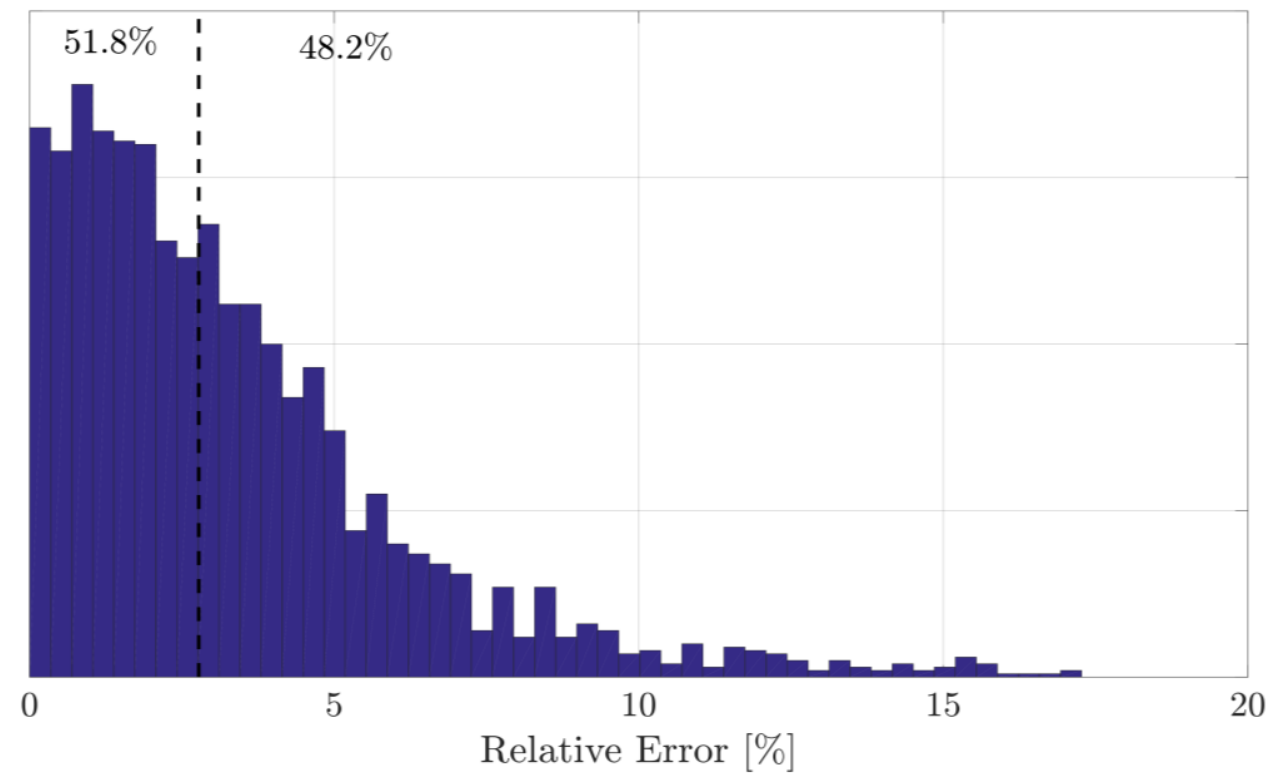

Fig. 9 - Relative error of the thermal efficiency (histogram) compared with the mean value of the uncertainty of the thermal efficiency (dashed line)

Fig. 9 explains the comparison between the relative error of thermal efficiency, calculated as the relative difference between the measured data and the estimated data using the linear regression, and the mean of the relative uncertainty calculated from the experimental data. It is possible to see that almost a half of the measured points have an error respect of the modeled curve that is lower than the uncertainty, which means the model in that cases predict correctly the thermal efficiency. 


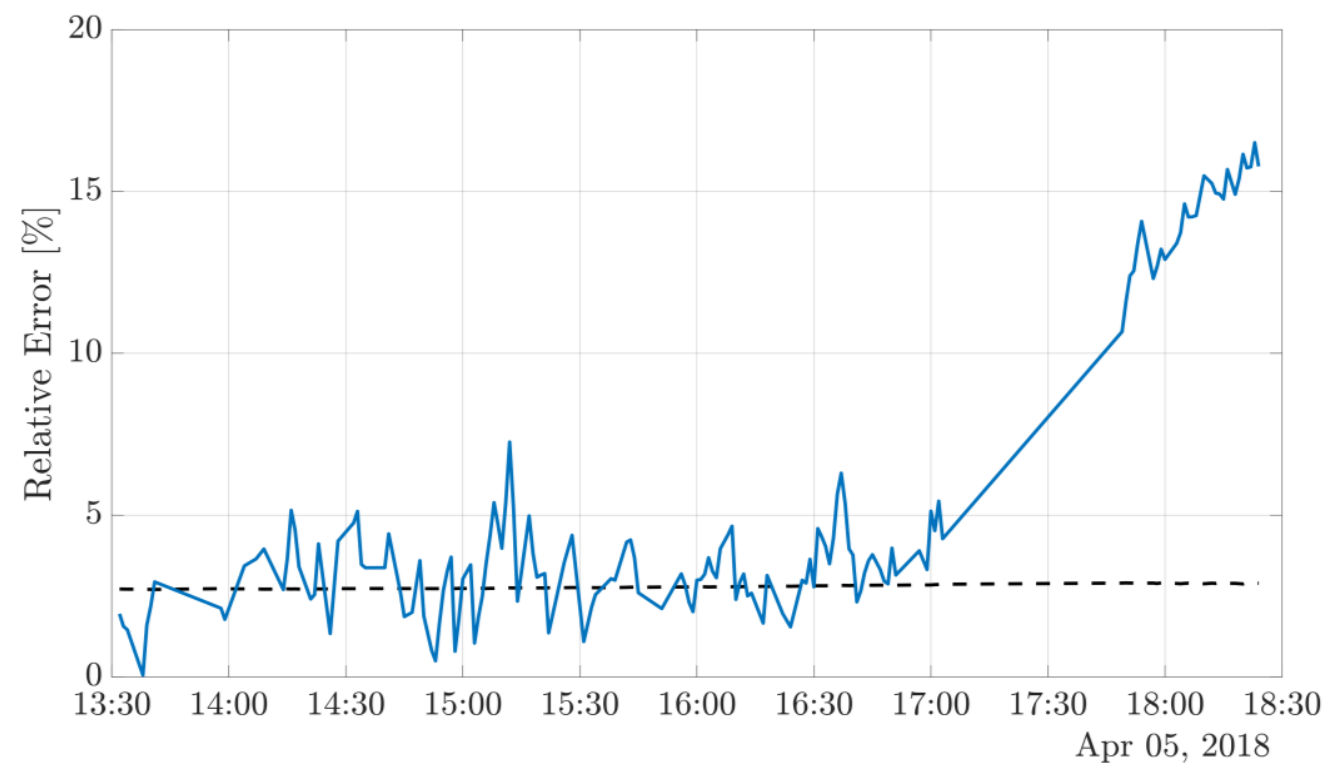

Fig. 10 - Relative error of thermal efficiency of a representative day (blue line) compared to uncertainty of thermal efficiency (dashed line)

This fraction is not prevalent (only $51.8 \%$ ) because the relative error is significantly higher than the uncertainty in the last part of the day (Fig. 10). This is caused by the reduction of solar irradiance and consequently the temperature difference between inlet and outlet of the solar panels, which penalizes the thermal power produced by PV/T modules and the power input from the Sun. To avoid this problem and measure correctly thermal efficiency also with very low reduced temperature, a solution can be the replacement of the HP with a greater one (in order to increase the cold heat required and consequently reduce the mean temperature of the $\mathrm{PV} / \mathrm{T}$ modules) or reduce the number of panels used to feed the HP.

\section{Conclusions}

In this paper, an experimental campaign was conducted at the laboratory SolarTech ${ }^{\mathrm{LAB}}$, Politecnico di Milano, for 20 days between March and April of 2018, to evaluate the behavior and the performance of four PV/T panels connected in parallel used as the cold source of a heat pump in different real ambient conditions, with particular focus on working conditions in which the mean temperature of the working fluid was below the ambient one. The experimental apparatus was built up with instruments that allow to measure inlet and outlet temperature of the modules, the volumetric flow rate, the electric production of each panel and the ambient conditions (solar irradiance and ambient temperature). A program developed with the software LabVIEW ${ }^{\mathrm{TM}}$ was used to control the laboratory, monitor the tests, collect the data and save them with a time step of one second. Furthermore, a filtering process was also worked out to remove all the measurements not in steady state conditions. Finally, uncertainty analysis was done to evaluate the goodness of the instruments and the measurement method.

Results shows that the behavior of PV/T modules follows the linear trend as the theory expose, also when the reduced temperature is very low. Thermal efficiency is higher than the optical one in several cases, reaching values of $200 \%$. Linear regression from the data has a very high $\mathrm{R}^{2}$ (up to 0.99 ) and the values of $\eta_{\text {opt }}$ and $\mathrm{a}_{1}$ are $49.7 \%$ and $-11.26 \mathrm{~W} /\left(\mathrm{m}^{2} \mathrm{~K}\right)$ respectively. Uncertainty analysis explains that the experimental apparatus is well build: in fact, the mean value of the uncertainty of thermal efficiency is $2.8 \%$. A possibility to reduce this value is findable changing the flow meter. Comparing the relative error between the measured value and the calculated from the regressed curve and the uncertainty, the work has shown that only half the points considered have a relative error lower than the uncertainty. Most of the other half points is concentrated in periods when the Sun is rising: in these conditions the difference between inlet and outlet temperature of PV/T panels is very limited and the error on the evaluation of the behavior of the system is reasonable greater.

The works finally evinces the scientific relevance to combine the PV/T technology with a HP, increasing the thermal efficiency due to the lower mean temperature of the working fluid and consequently increasing the electrical production, extending the utilization of PV/T panels also in the cold period. 


\section{References}

Aste, N., Del Pero, C. \& Leonforte, F., 2014. Water flat plate PV-thermal collectors. A review. Solar Energy, Volume 102, pp. 98-115, DOI: http://dx.doi.org/10.1016/j.solener.2014.01.025.

Calise, F., Dentice d'Accadia, M., Figaj, R. \& Vanoli, L., 2016. A novel solar-assisted heat pump driven by photovoltaic/thermal collectors: Dynamic simulation and thermoeconomic optimization. Energy, Volume 95, pp. 346-366, DOI: https://doi.org/10.1016/j.energy.2015.11.071.

Chow, T. T., 2010. A review on photovoltaic/thermal hybrid solar technology. Applied Energy, 87(2), pp. 365379, DOI: http://dx.doi.org/10.1016/j.apenergy.2009.06.037.

Ji, J. et al., 2008. Experimental study of photovoltaic solar assisted heat pump system. Solar Energy, Volume 82, pp. 43-52, DOI: https://doi.org/10.1016/j.solener.2007.04.006.

Kim, J. \& Kim, J., 2012. The experimental performance of an unglazed PV-thermal collector with a fully wetted absorber. Energy Procedia, Volume 30, pp. 144-151, DOI: http://dx.doi.org/10.1016/j.egypro.2012.11.018.

Kumar, A., Baredar, P. \& Qureshi, U., 2015. Historical and recent development of photovoltaic thermal (PVT) technologies. Renewable and Sustainable Energy Reviews, Volume 42, pp. 1428-1436, DOI: http://dx.doi.org/10.1016/j.rser.2014.11.044.

Li, H., Sun, L. \& Zhang, Y., 2014. Performance investigation of a combined solar thermal heat pump heating system. Applied Thermal Engineering, 71(1), pp. 460-468, DOI: https://doi.org/10.1016/j.applthermaleng.2014.07.012.

Migliorini, L., Molinaroli, L., Simonetti, R. \& Manzolini, G., 2017. Development and experimental validation of a comprehensive thermoelectric dynamic model of photovoltaic modules. Solar Energy, Volume 144, pp. 489-501, DOI: https://doi.org/10.1016/j.solener.2017.01.045.

Simonetti, R., Manzolini, G. \& Molinaroli, L., 2017. Modeling of Solar Assisted Heat Pumps Combined with Photovoltaic Thermal Modules. Proceedings of SWC2017/SHC2017, pp. 1-12, DOI: https://doi.org/10.18086/swc.2017.33.08.

SoLink, 2017. SoLink PVT. [Online] Available at: http://www.solink.it [Accessed 5 September 2018].

Zondag, H., De Vries, D., Van Helden, W. \& Van Zolingen, R., 2003. The yield of different combined PVthermal collector designs. Solar Energy, Volume 74, pp. 253-269, DOI: https://doi.org/10.1016/S0038092X(03)00121-X. 